\title{
Predictors of Prolonged Mechanical Ventilation Among Patients with Aneurysmal Subarachnoid Hemorrhage After Microsurgical Clipping
}

\author{
Ching-Hua Huang · Shih-Ying Ni · Hsueh-Yi Lu • Abel Po-Hao Huang • \\ Lu-Ting Kuo (D)
}

Received: December 20, 2021 / Accepted: February 7, 2022 / Published online: February 20, 2022

(C) The Author(s) 2022

\begin{abstract}
Introduction: Aneurysmal subarachnoid hemorrhage (aSAH) is a fatal event with high mortality and morbidity rates. Survivors may require prolonged intubation with mechanical ventilation (MV). However, the risk factors for prolonged intubation in these patients remain unclear. The aim of this study was to determine the predictors of prolonged $\mathrm{MV}$ in aSAH patients who underwent surgical clipping.

Methods: In total, 108 adult patients with a primary diagnosis of aSAH who were on MV $>48 \mathrm{~h}$ and survived $>14$ days after surgery
\end{abstract}

C.-H. Huang · A. P.-H. Huang · L.-T. Kuo $(\bowtie)$ Division of Neurosurgery, Department of Surgery, National Taiwan University Hospital, 7 Chung-Shan South Road, Taipei 100, Taiwan

e-mail: kuoluting@gmail.com

C.-H. Huang

e-mail: glen7991@gmail.com

A. P.-H. Huang

e-mail: how.how0622@gmail.com

S.-Y. Ni

Department of Psychiatry, National Taiwan

University Hospital, Taipei, Taiwan

e-mail: b02401027@ntu.edu.tw

H.-Y. Lu

Department of Industrial Engineering and

Management, National Yunlin University of Science and Technology, Yunlin, Taiwan

e-mail: hylu@yuntech.edu.tw were included. Clinicodemographic and radiological characteristics, laboratory tests on admission, and initial Glasgow Coma Scale (GCS) and its components were analyzed.

Results: The average age of the patients included in the analysis was $59.1 \pm 12.5$ years. Overall, 32 patients (29.6\%) had prolonged MV. The group with prolonged MV showed a higher prevalence of diabetes mellitus and hypertension, lower initial GCS and its components, higher World Federation of Neurosurgeons (WFNS) and Hunt and Hess grades, and higher initial white cell counts. The independent factors associated with prolonged MV were a history of diabetes mellitus (odds ratio [OR] 5.799, 95\% confidence interval [CI] 1.109-30.334; $P=0.037)$ and Hunt and Hess grade $3-5$ (OR 7.217, 95\% CI 1.090-47.770; $P=0.040$ ).

Conclusion: A history of diabetes mellitus and Hunt and Hess grade 3-5 independently predict prolonged MV after microsurgical clipping in patients with aSAH. Thus, knowledge of potential predictors for prolonged MV is essential to improve the early initiation of adequate treatment in the early stages of treatment and provide useful information for communication between caregivers and families.

Keywords: Aneurysmal subarachnoid hemorrhage; Hunt and Hess grade; Mechanical ventilation; Microsurgical clipping 


\section{Key Summary Points}

\section{Why carry out this study?}

Survivors of aneurysmal subarachnoid hemorrhage (aSAH) may require prolonged intubation with mechanical ventilation $(\mathrm{MV})$.

However, the risk factors for prolonged intubation in these patients are still unclear.

\section{What was learned from this study?}

A history of diabetes mellitus and Hunt and Hess grade 3-5 independently predict prolonged $\mathrm{MV}$ in aSAH patients.

Predicting the possibility of prolonged MV can help neurocritical patients benefit from tracheostomy and avoid unnecessary complications.

\section{INTRODUCTION}

Aneurysmal subarachnoid hemorrhage (aSAH) is a neurological emergency that occurs in 9-10/ 100,000 persons per year $[1,2]$. Despite advances in neurocritical care, the mortality and morbidity rates of aSAH remain high, accounting for $2-5 \%$ of strokes [3-5]. Survivors frequently have long-term disabilities. Age, aneurysm size, Fisher grade, Hunt and Hess grade, World Federation of Neurosurgeons (WFNS) grade, presence of intracerebral hemorrhage (ICH), and Glasgow Coma Scale (GCS) have been found to influence aSAH outcomes [6-9]. Microsurgical clipping and endovascular therapy with coiling are the main treatment modalities for ruptured aneurysms. In such situations, generalized anesthesia with mechanical ventilation (MV) is required. In addition, patients are usually intubated endotracheally with MV for respiratory failure, airway protection, or altered mental status. Delayed cerebral ischemia is a common and detrimental complication after aSAH, which results in secondary brain injury [2, 10-12].

Patients with severe brain injury may have longer durations of MV use and poorer outcomes than the general population of intensive care unit (ICU) patients [13, 14]. Specific recommendations regarding weaning from MV for the patient population with aSAH are still lacking. In addition, the risk of ventilator-associated pneumonia (VAP) is increased by delayed extubation despite meeting the readiness criteria [14]. Other significant complications of prolonged MV, including airway injury, ventilator-associated lung injury, and prolonged immobility, incur significant social and economic burdens $[15,16]$. Predictive models of prolonged MV in aSAH patients after microsurgical clipping can provide useful information to facilitate the management of these patients in the ICU and help patient families and caregivers to better anticipate the treatment course and decision-making. However, only a few studies have analyzed the risk factors for prolonged intubation in these patients. Thus, this study aimed to determine the predictors of prolonged MV in aSAH patients who underwent surgical clipping. We hypothesize that aSAH patients with higher disease severity and comorbidities need prolonged MV after surgery.

\section{METHODS}

\section{Study Design and Patients}

This retrospective observational study was conducted at the National Taiwan University Hospital. We evaluated adult patients (age $\geq 18$ years) with aSAH who were admitted to the neurosurgical ICU after microsurgical clipping, endotracheally intubated for at least $48 \mathrm{~h}$ of $\mathrm{MV}$, and survived $>14$ days between May 2015 and December 2019. Only patients who underwent microsurgical clipping of the aneurysms were included. In contrast, patients with endovascular coiling of the aneurysm, iatrogenic aneurysm rupture, pre-existing brain diseases (stroke, brain tumor, or meningitis), substance abuse disorders (illicit drugs or alcohol), and history of lung surgery or 
Table 1 Patient characteristics $(n=108)$

\begin{tabular}{|c|c|}
\hline Variable & Value \\
\hline Age (years) & $59.05 \pm 12.52$ \\
\hline Sex, male & $30(27.8)$ \\
\hline Weight (kg) & $62.10 \pm 12.44$ \\
\hline $\mathrm{DM}$ & $13(12 \%)$ \\
\hline $\mathrm{HTN}$ & $52(48.1)$ \\
\hline Initial E & $3.06 \pm 1.23$ \\
\hline Initial $\mathrm{M}$ & $5.2 \pm 1.34$ \\
\hline Initial $\mathrm{V}$ & $3.33 \pm 1.87$ \\
\hline Initial GCS & $11.6 \pm 3.98$ \\
\hline Initial WBC & $13.24 \pm 5.26$ \\
\hline Initial $W B C>10,000$ & $72(66.7)$ \\
\hline Initial WBC $>12,000$ & $57(52.8)$ \\
\hline Initial WBC $>15,000$ & $35(32.4)$ \\
\hline \multicolumn{2}{|l|}{ Location of aneurysm } \\
\hline Anterior circulation & $104(96.3)$ \\
\hline Posterior circulation & $4(3.7)$ \\
\hline EVD for hydrocephalus & $69(63.8)$ \\
\hline \multicolumn{2}{|l|}{ Hunt and Hess scale } \\
\hline Grade $1-2$ & $52(48.1)$ \\
\hline Grade 3-5 & $56(51.9)$ \\
\hline \multicolumn{2}{|l|}{ WFNS scale } \\
\hline Grade 1-2 & $58(53.7)$ \\
\hline Grade 3-5 & $50(46.3)$ \\
\hline \multicolumn{2}{|l|}{ Modified Fisher grade } \\
\hline Grade 1-2 & $25(23.1)$ \\
\hline Grade 3-4 & $83(76.9)$ \\
\hline Extubation failure (re-intubation) & $3(2.8)$ \\
\hline$M V \geq 14$ days & $32(29.6)$ \\
\hline
\end{tabular}

Data are presented as the mean \pm standard deviation (SD) or as $n(\%)$

$D M$ Diabetes mellitus, $G C S$ Glasgow Coma Scale ( $E$ eye opening, $M$ motor response, $V$ verbal response), $H T N$ hypertension, $M V$ mechanical ventilation, $W B C$ white blood cell, WFNS World Federation of Neurosurgeons tracheostomy, those intubated for $<48 \mathrm{~h}$ of MV after aSAH, and those lost to follow-up were excluded. Patients with incomplete or unavailable records and who signed a do-not-resuscitate order were also excluded.

This study was approved by the Institutional Review Board of National Taiwan University Hospital (IRB number: 201611058RINA). The study was conducted in accordance with the applicable local regulations and the Declaration of Helsinki of 1964 and subsequent revisions and in accordance with the STROBE guidelines. Written informed consent was obtained from the patients. If the patients were comatose, consent was obtained from the patients' caregivers.

\section{Assessment and Data Collection}

aSAH was defined as the diagnosis of an aneurysm with an associated non-traumatic SAH presentation based on imaging studies. All patients were followed up for at least 14 days until they had undergone spontaneous breathing trials (SBTs) and passed the weaning parameters before extubation or were confirmed to be dependent on MV > 2 weeks after endotracheal intubation. All patients underwent computed tomography angiography (CTA) in the emergency department to confirm subarachnoid hemorrhage caused by ruptured aneurysms.

All data were collected and reviewed using an electronic medical record system. We collected the following information for each patient: demographic data, medical history of hypertension or diabetes mellitus (DM), radiographic data for grading, laboratory data upon emergency department arrival, imaging data, and aneurysm-related information.

\section{Surgical Procedure, Assessments, and Postoperative Care}

The choice between endovascular coiling and microsurgical clipping to manage aneurysms was made by neurosurgeons and interventional neuroradiologists. External ventricular drains (EVD) were placed in patients with acute 
hydrocephalus after aSAH. MV is essential for aSAH patients to prevent secondary brain damage by providing adequate oxygenation and ventilation and to administer general anesthesia for surgery. The intensive care of these patients was managed according to international guidelines [17]. All hyperglycemic patients were treated with insulin therapy to achieve a target blood sugar level $\leq 200 \mathrm{mg} / \mathrm{dL}$ with strict prevention of hypoglycemia during postoperative care. All patients received nimodipine at a dose of $2 \mathrm{mg} / \mathrm{h}$ to prevent vasospasm when the oral route was not available and if patients had delayed cerebral ischemia (DCI).

Postoperatively, patients were continuously monitored in the ICU to detect any clinical deterioration. Postoperative management included $\mathrm{MV}$, antiepileptic drugs, antibiotic prophylaxis for at least 3 days, and early enteral nutrition using a nasogastric or orogastric tube. Neurological assessments were performed hourly, including the GCS, pupil size, and reaction to light. When vasospasm or DCI was suspected, CTA or conventional digital subtraction angiography was used to confirm the diagnosis and rule out other differential diagnoses.

\section{Measurement of Weaning Parameters}

Once the patient was stabilized postoperatively, MV support was gradually reduced to start the transition from controlled ventilation to spontaneous ventilation. When the patients could tolerate the reduced applied airway pressure support of $5-10 \mathrm{~cm}$ of water, an SBT using a T-tube (T-piece) was performed to spontaneously assess the ability to breathe. The respiratory therapist measured the weaning parameters, including maximal inspiratory pressure (PiMax), maximal expiratory pressure (PeMax), respiratory rate (RR), rapid shallow breathing index (RSBI), minute ventilation (VE), and tidal volume (VT), using a standardized method.

The cutoff points of weaning parameters used to evaluate the general patients under MV in our hospital were as follows: PiMax -30
$\mathrm{cmH}_{2} \mathrm{O}$; PeMax $30 \mathrm{cmH}_{2} \mathrm{O} ; \mathrm{RSBI}<105 ; \mathrm{RR}<30$ breaths/min; $\mathrm{VE}<10 \mathrm{~L} / \mathrm{min}$; and $\mathrm{VT}>5 \mathrm{~mL} /$ $\mathrm{kg}$. The endotracheal tube was removed if the patient had all of the aforementioned parameter values and passed the SBT. If the patients did not require re-intubation after monitoring respiratory conditions for $48 \mathrm{~h}$, the weaning process was regarded as successful. Moreover, if the patients could not be extubated 14 days after the initiation of MV, they were included in the prolonged MV group.

\section{Statistical Analyses}

We analyzed sociodemographic data (age, sex, body weight, DM, and hypertension), clinicoradiological variables (GSC and its components, Hunt and Hess grade, the WFNS grade, and modified Fisher grade), and peripheral white blood cell count (WBC) at admission. Continuous variables were presented as the mean $\pm s$ tandard deviation (SD) in the descriptive analyses, while categorical and binary variables were presented as frequencies $(n)$ and percentages (\%). Student's $t$-test and Chi-squared test were used to compare outcomes between patient subgroups for continuous and categorical data, respectively. Univariate analyses were performed using logistic regression analysis to identify the independent prognostic variables. Significant variables in the univariate analysis (i.e., those with a $P<0.10$ ) were entered into the multivariate logistic regression with stepwise selection to identify the independent predictors of prolonged MV. All statistical analyses were performed using SPSS version 26 for Windows (SPSS IBM Corp., Armonk, NY, USA). Statistical significance was set at $P<0.05$.

\section{RESULTS}

\section{Patient Characteristics}

In total, 108 aSAH patients with a mean $( \pm \mathrm{SD})$ age of $59.05 \pm 12.52$ years were included (Table 1). The majority of the patients were female $(72.2 \%, n=78)$, and the mean GCS at admission was $11.6 \pm 3.98$. There were 104 
Table 2 Univariate analysis of the factors associated with prolonged mechanical ventilation $(n=108)$

\begin{tabular}{llll}
\hline Variable & MV $\geq \mathbf{1 4}$ days $(\boldsymbol{n}=\mathbf{3 2})$ & $\mathbf{M V}<\mathbf{1 4}$ days $(\boldsymbol{n}=\mathbf{7 6})$ & $\boldsymbol{P}$ value \\
\hline Age (years) & $63.69 \pm 11.68$ & $57.09 \pm 12.41$ & $0.012^{*}$ \\
Sex, male & $9(28.1)$ & $21(27.6)$ & 0.960 \\
Weight $(\mathrm{kg})$ & $64.00 \pm 12.39$ & $61.31 \pm 12.45$ & 0.306 \\
DM & $8(25.0)$ & $5(6.6)$ & $0.007^{*}$ \\
HTN & $21(65.6)$ & $32(42.1)$ & $0.026^{*}$ \\
Initial E & $2.47 \pm 1.32$ & $3.32 \pm 1.11$ & $0.001^{*}$ \\
Initial M & $4.81 \pm 1.33$ & $5.37 \pm 1.32$ & $0.048^{*}$ \\
Initial V & $2.31 \pm 1.66$ & $3.76 \pm 1.80$ & $0.000^{* *}$ \\
Initial GCS & $9.59 \pm 3.78$ & $12.45 \pm 3.78$ & $0.001^{*}$ \\
Initial WBC & $14.81 \pm 5.97$ & $12.58 \pm 4.83$ & $0.045^{*}$ \\
Initial WBC $>10,000$ & $24(75.0)$ & $48(63.2)$ & 0.233 \\
Initial WBC $>12,000$ & $21(65.6)$ & $36(47.4)$ & 0.083 \\
Initial WBC $>15,000$ & $15(46.9)$ & $20(26.3)$ & $0.037^{*}$ \\
EVD & $24(75.0)$ & $44(57.9)$ & 0.119 \\
Hunt and Hess grade 3-5 & $27(84.4)$ & $29(38.2)$ & $0.000^{* *}$ \\
WFNS scale score 3-5 & $24(75.0)$ & $26(34.2)$ & $0.000^{* *}$ \\
Modified Fisher Grade (III, IV) & $28(87.5)$ & $55(72.4)$ & 0.089 \\
\hline Din & &
\end{tabular}

Data are presented as the mean \pm SD or as $n(\%)$

, ${ }^{*}$ Significant difference at ${ }^{*} P<0.05$ and ${ }^{* *} P<0.001$

$E V D$ External ventricular drain

$(96.3 \%)$ and four (3.7\%) patients with anterior and posterior circulation aneurysms, respectively. All patients underwent microsurgical clipping of the ruptured aneurysms, and 69 of them underwent placement of EVD for acute hydrocephalus. Thirty-three $(30.5 \%)$ patients were diagnosed with DCI 4-12 days after aSAH and surgical clipping. We diagnosed brain tissue injuries, including cerebral edema and hemorrhagic contusions, in nine $(8.3 \%)$ patients, stroke in six $(5.6 \%)$ patients, and deep vein thrombosis in the lower extremities in three (1.9\%) patients. Overall, $32(29.6 \%)$ patients were mechanically ventilated for $>14$ days. During postoperative intensive care, 79 patients (73.1\%) were weaned off MV after passing the SBT within 14 days after surgery. The majority of these patients $(96.2 \%, n=76)$ had successful extubation without re-intubation, and only three patients were re-intubated within $72 \mathrm{~h}$ after extubation.

\section{Factors Associated with Prolonged MV}

Prolonged MV ( $\geq 14$ days) was observed in 32 patients (29.6\%). Patient characteristics of short MV group ( $<14$ days) and the prolonged MV group are compared in Table 2. Compared to the short MV group, the prolonged MV group was significantly older (63.69 vs. 57.09 years; $P=0.012)$, with a higher rate of DM (25.0 vs. $6.6 \% ; P=0.007)$, a significantly lower initial GCS before surgery (9.59 vs. $12.45 ; P=0.001)$, significantly higher initial WBC counts $(14.81 \times$ 
Table 3 Multivariate analysis of the factors associated with prolonged intubation

\begin{tabular}{lcll}
\hline Factors & Exp $(\boldsymbol{B})$ & $\mathbf{9 5 \%}$ Confidence interval & $\boldsymbol{P}$ value \\
\hline Age (years) & 1.044 & $0.992-1.099$ & 0.100 \\
DM & 5.799 & $1.109-30.334$ & $0.037^{*}$ \\
HTN & 1.856 & $0.575-5.997$ & 0.301 \\
Initial GCS & 0.929 & $0.793-1.088$ & 0.361 \\
Initial WBC > 15 K & 2.534 & $0.825-7.785$ & 0.104 \\
Hunt and Hess grade 3-5 & 7.217 & $1.090-47.770$ & $0.040^{*}$ \\
WFNS 3-5 & 13.64 & $0.254-7.319$ & 0.718 \\
\hline
\end{tabular}

*Significant at $P<0.05$

$10^{3}$ vs. $\left.12.58 \times 10^{3} ; P=0.045\right)$, a higher percentage of patients with Hunt and Hess grade $>2(84.4$ vs. $38.2 \% ; P<0.001)$, and a higher percentage of patients with WFNS grade $>2$ (75.0 vs. $34.2 \% ; P<0.001)$. All components of the initial GCS were also lower in this group (all $P<0.05$ ). When WBC counts were dichotomized at $15,000 / \mu \mathrm{L}$, the prolonged MV group included a higher percentage of patients with high initial WBC counts (46.9 vs. $26.3 \%$ ). There was no significant between-group difference with respect to sex, body weight, or modified Fisher grade.

To identify the independent prognostic variables, multivariate regression analysis was performed using variables with a $P<0.10$ in the univariate analysis. In the multivariate analysis, a history of DM (odds ratio [OR] 5.799, 95\% confidence interval [CI] 1.109-30.334; $P=0.037)$ and Hunt and Hess grade 3-5 (OR 7.217, 95\% CI 1.090-47.770; $P=0.040$ ) independently influenced the incidence of prolonged MV. Meanwhile, age (OR 1.044, 95\% CI 0.992-1.099; $P=0.100$ ), hypertension (OR 1.856, 95\% CI 0.575-5.997; $P=0.301)$, initial GCS (OR 0.929, 95\% CI 0.793-1.088; $P=0.361$ ), initial $\mathrm{WBC}>15,000 \quad(\mathrm{OR} 2.534,95 \% \quad \mathrm{CI}$ $0.825-7.785 ; P=0.104)$, and WFNS grade (OR 13.64, 95\% CI 0.254-7.319; $P=0.718$ ) had no influence on prolonged MV incidence (Table 3).

\section{DISCUSSION}

Despite the importance of predictors of prolonged MV in facilitating the management of patients with aSAH, there are only a limited number of studies analyzing the risk factors for prolonged intubation in these patients. In this study we found that DM and Hunt and Hess grades were significantly associated with prolonged MV. To the best of our knowledge, this is the first study to provide a comprehensive characterization and analysis of the predictors of prolonged MV in patients who underwent microsurgical clipping to secure cerebral aneurysms (CAs) after aSAH.

Only patients who underwent clipping surgery after aSAH were included in the analysis. We focused on the unique considerations relating to airway management and analyzed prolonged $\mathrm{MV}$ in the aSAH population after microsurgery. Considering the deficits in neurological functions and changes in consciousness after aSAH, these patients may be weaned off MV when they pass the screen of weaning parameters. However, they may need re-intubation or continue to require an artificial airway. Based on the weaning parameters for the general critical care patients (PiMax - 30 $\mathrm{cmH}_{2} \mathrm{O}$, PeMax $30 \mathrm{cmH}_{2} \mathrm{O}, \mathrm{RSBI}<105, \mathrm{RR}<30$ breaths/min, $\mathrm{VE}<10 \mathrm{~L} / \mathrm{min}$, and $\mathrm{VT}>5 \mathrm{~mL} /$ $\mathrm{kg}), 79(73.1 \%)$ patients were extubated after passing the SBT; however, three $(3.8 \%)$ of these patients were re-intubated within $72 \mathrm{~h}$. 
Management guidelines for CAs have been developing continuously since the 1990s [18-20]. CAs are treated either surgically or endovascularly, and treatment decisions should consider the location and morphology of the aneurysms, comorbidities, or the need for emergency surgical hematoma evacuation. Critically ill patients on prolonged MV have significantly higher morbidity and mortality, and tracheostomy should be indicated [21]. Compared with prolonged use of a translaryngeal tube, a tracheostomy with decreased airway resistance can better accelerate the weaning process and the rate of success, improve patient comfort, and decrease in-hospital mortality and the duration of hospitalization $[22,23]$.

However, a limited number of studies have analyzed the risk factors for tracheostomy and prolonged intubation in patients with aSAH. In $\mathrm{ICH}$, other risk factors for prolonged intubation include hematoma location, hydrocephalus, chronic obstructive pulmonary disease, and obesity [24-26]. Unlike other forms of stroke, DCI and increased intracranial pressure from hydrocephalus should be considered during the treatment course after the ruptured aneurysm has been secured. Neurogenic pulmonary edema and respiratory distress syndrome occur in $20-23 \%$ [26-28] and $18-50 \%$ [29-31] of aSAH patients, respectively. In a study of 146 patients with poor-grade aSAH, Gessler et al. demonstrated that tracheostomy within 1 week was associated with a lower possibility of pneumonia and shorter MV but did not affect ICU length of stay, neurological function, or mortality [32].

The results of another study showed that a later tracheostomy in poor-grade aSAH patients was associated with longer hospitalization, venous thromboembolic events, and pneumonia [33]. Also, in a study comparing 1069 patients who underwent endovascular approach and 519 patients who underwent surgical approach after aSAH, rates of $\mathrm{MV}$, pneumonia, deep vein thrombosis, and tracheostomy were higher in patients treated surgically [34]. Of the patients in these two treatment groups, $27.6 \%$ and $42.4 \%$ underwent $\mathrm{MV}>4$ days, and $19 \%$ and $32.4 \%$ patients underwent tracheostomy after prolonged MV, respectively [34]. The reasons for the disadvantage of craniotomy over the endovascular approach remain unclear, and further research is needed to understand the surgery-related physiological changes to discover the specific patient group requiring a tailored treatment.

In general, intubation is indicated in aSAH patients with GCS $\leq 8$, elevated intracranial pressure, status epilepticus, elective surgical intervention, poor oxygenation or hypoventilation, hemodynamic instability, and a need for therapeutic hyperventilation or demand for heavy sedation $[35,36]$. Furthermore, weaning off $\mathrm{MV}$ is a crucial process in these patients when the ruptured aneurysms are secured from rebleeding, their cardiovascular condition stabilizes, and they do not deteriorate neurologically and have an adequate gas exchange. Patients requiring prolonged MV are prone to skeletal muscle atrophy due to limited physical activity, respiratory muscle weakness, and many other complications, which can be improved by early weaning and physical rehabilitation $[15,16,37]$.

Patients are first assessed for their readiness to wean based on satisfactory weaning parameters and an SBT, followed by the decision regarding possible extubation [38, 39]. Weaning parameters are used to evaluate respiratory physiology capacity and the ability to breathe adequately without assistance. The commonly used weaning parameters include PiMax, PeMax, VT, VE, RR, RSBI, airway resistance, and compliance [40, 41]. Compared to critically ill patients requiring MV due to other diseases, patients with aSAH and impaired consciousness may have a low respiratory drive and impaired coughing reflex to clear secretions and protect the airway, and these cannot be assessed by weaning parameters. Therefore, even if patients pass the weaning parameters, they may develop extubation failure and require re-intubation and MV for adequate airway protection and oxygenation [42, 43]. Additionally, these patients may benefit from continued endotracheal intubation to prevent aspiration and maintain the ability to suction secretions until the improvement of neurological functions.

The plasma glucose level at admission is an independent predictor of prognosis after 
myocardial infarction, coronary artery bypass graft surgery, and traumatic brain injuries, and in critically ill patients [44-48]. In a study of 228 patients with endogenous diseases aged $\geq 75$ years, DM was an independent predictor of extubation difficulty, including the use of MV > 14 days, re-intubation within $48 \mathrm{~h}$ after extubation, and tracheotomy [49]. In a metaanalysis of 39 studies involving 359,783 patients with ischemic and hemorrhagic stroke, DM was prevalent in $28 \%$ of the patients [50]. Most of the included studies found that DM was associated with higher mortality, poor functional outcomes, and longer hospital stays. In a retrospective study of 2540 aSAH patients, 9.4\% of whom had DM, long-term MV was an independent predictor of poor functional outcome [34]. Patients with hyperglycemia have an approximately threefold increased risk for poor outcome after aSAH [51, 52]. In our study, 12\% of the aSAH patients had a history of DM, which was a significant predictor of prolonged MV. The DCI usually occurs in $30-40 \%$ of aSAH patients, mostly between days 4 and 10, and it can progress to irreversible cerebral infarction with subsequent poor clinical outcomes [53-55]. The authors of a systemic review concluded that there is an increased risk of DCI in patients with hyperglycemia (OR 3.2, 95\% CI 1.8-5.8) and history of DM (pooled OR 6.7, 95\% CI 1.7-26) [56]. DCI, which is the leading cause of secondary neurological deficits after aSAH, may be one of the factors associated with the pathophysiology of prolonged MV after aSAH.

Grading systems based on initial evaluation and imaging findings have been used to classify patients with aSAH. The most widely used grading systems are the Hunt and Hess grading system, Fisher grade, and the WFNS grading system. The Hunt-Hess and WFNS scales are the most widely used grading systems for clinical assessments in patients with aSAH. They primarily focus on the consciousness and neurological deficits that reflect the severity of brain injury [57]. In contrast, the modified Fisher scale is a commonly accepted radiological grading system that assesses the severity of brain injury by quantifying the amount and distribution of hemorrhage on computed tomography images to predict the incidence of vasospasm and DCI [58]. A higher Hunt and Hess grade implies a decreased level of consciousness and focal neurologic deficits, which may lead to impaired protective reflexes and an increased risk of aspiration.

A retrospective study of 669 aSAH patients compared the performances of different grading scores for predicting functional outcomes between patients who underwent microsurgical clipping and endovascular coiling. The results demonstrated that the clinical grading systems have significantly better predictive performance than the radiological grading systems in both groups [59]. These results are supported by other studies $[60,61]$. A higher score on the WFNS scale, which uses the GCS and focal neurological deficits to grade the severity of aSAH, independently predicted prolonged intubation in patients with aSAH after surgical or endovascular treatment [62]. Rass et al. reported that a higher Hunt and Hess grade in aSAH patients was associated with an MV $>7$ and 14 days [63]. Consistent with this, the current study found that a Hunt and Hess scale grade of 3-5 was an independent predictor of prolonged MV after clipping in aSAH patients. In contrast, modified Fisher grade (dichotomized to grade 1-2 and grade 3-4) was not significantly associated with prolonged $\mathrm{MV}$ in both the univariate and multivariate analyses. The WFNS scale score, as a clinical score, was significantly associated with MV in the univariate analysis but not in the multivariate analysis. These findings emphasize the importance of using different scoring systems for predicting different aspects of outcomes after aSAH.

As a common hospital-acquired infection after $>48 \mathrm{~h}$ of MV use, VAP is the leading cause of death from nosocomial infections in critically ill patients [64]. It is associated with prolonged hospitalization and increased healthcare costs, morbidity, and mortality $[65,66]$. In patients on $\mathrm{MV}$, the incidence of VAP increases with the duration of ventilation at approximately $1.5 \%$ per day [67]. With late tracheostomy or prolonged $\mathrm{MV}$ as a reference, early tracheostomy in patients requiring intensive care who are on $\mathrm{MV}$ at $\leq 7$ days and $\leq 10$ days after intubation have no significant benefits with respect to the length of ICU 
stay, hospital stay, duration of MV use, or survival [68-70]. Further, it is important to predict the possibility of prolonged MV in neurocritical patients and determine the necessity and timing of tracheostomy. This can help patients benefit from tracheostomy and avoid unnecessary complications.

This study has some limitations. First, our data were collected retrospectively from a single institution. Thus, important confounders relevant to the results may have been missed. Therefore, future studies involving larger populations are needed to validate the generalizability of our results. Second, the patients were treated surgically by three neurosurgeons, and the postoperative treatment strategy may have varied. Third, not all patients had their blood sugar and glycated hemoglobin levels measured on arrival to the emergency room, which limited further detailed analysis of diabetic patients. Despite these limitations, this study remains valuable as it investigates an important aspect of MV use in a selected patient cohort and provides baseline evidence for further studies to improve the outcomes of aSAH patients.

\section{CONCLUSION}

In conclusion, a history of DM and Hunt and Hess grade 3-5 independently predict prolonged MV after microsurgical clipping in patients with aSAH. This finding may help to improve current weaning protocols and provide useful information to help both clinicians and families in better clinical decision-making.

\section{ACKNOWLEDGEMENTS}

We thank the participants of the study.

Funding. No funding or sponsorship was received for this study or publication of this article. Lu-Ting Kuo, the corresponding author, provided funding for the Rapid Service Fee associated with the publication of this manuscript.
Editorial Assistance. We would like to thank Editage. (http://www.editage.com) for English language editing. Lu-Ting Kuo, the corresponding author, provided funding for the English language editing assistance from Editage.

Authorship. All named authors meet the International Committee of Medical Journal Editors (ICMJE) criteria for authorship for this article, take responsibility for the integrity of the work as a whole, and have given their approval for this version to be published.

Author Contributions. All authors contributed to the study conception and design. Lu-Ting Kuo contributed to the study conception and design. Material preparation, data collection, and analysis were performed by Ching-Hua Huang, Shih-Ying Ni, Hsueh-Yi Lu, and Abel Po-Hao Huang. The first draft of the manuscript was written by Ching-Hua Huang and Lu-Ting Kuo, and all authors commented on the previous versions of the manuscript. All authors read and approved the final manuscript.

Disclosures. Ching-Hua Huang, Shih-Ying $\mathrm{Ni}$, Hsueh-Yi Lu, Abel Po-Hao Huang and LuTing Kuo declare that they have no conflict of interest.

Compliance with Ethics Guidelines. This study was approved by the institutional review board of National Taiwan University Hospital (IRB number: 201611058RINA). The study was conducted in accordance with the applicable local regulations and the Declaration of Helsinki of 1964 and subsequent revisions and in accordance with the STROBE guidelines. Written informed consent was obtained from the patients. If the patients were comatose, consent was obtained from the patients' caregivers.

Data Availability. The manuscript has no associated data or the data will not be deposited.

Open Access. This article is licensed under a Creative Commons Attribution- 
NonCommercial 4.0 International License, which permits any non-commercial use, sharing, adaptation, distribution and reproduction in any medium or format, as long as you give appropriate credit to the original author(s) and the source, provide a link to the Creative Commons licence, and indicate if changes were made. The images or other third party material in this article are included in the article's Creative Commons licence, unless indicated otherwise in a credit line to the material. If material is not included in the article's Creative Commons licence and your intended use is not permitted by statutory regulation or exceeds the permitted use, you will need to obtain permission directly from the copyright holder. To view a copy of this licence, visit http:// creativecommons.org/licenses/by-nc/4.0/.

\section{REFERENCES}

1. Suarez JI, Tarr RW, Selman WR. Aneurysmal subarachnoid hemorrhage. N Engl J Med. 2006;354: 387-96. https://doi.org/10.1056/NEJMra052732.

2. Macdonald RL. Delayed neurological deterioration after subarachnoid haemorrhage. Nat Rev Neurol. 2014;10:44-58. https://doi.org/10.1038/nrneurol. 2013.246 .

3. Nagahama Y, Allan L, Nakagawa D, et al. Dual antiplatelet therapy in aneurysmal subarachnoid hemorrhage: association with reduced risk of clinical vasospasm and delayed cerebral ischemia. J Neurosurg. 2018;129:702-10. https://doi.org/10. 3171/2017.5.JNS17831.

4. Bogason ET, Anderson B, Brandmeir NJ, et al. The epidemiology of admissions of nontraumatic subarachnoid hemorrhage in the United States. Neurosurgery. 2014;74:227-9. https://doi.org/10.1227/ NEU.0000000000000240.

5. Broderick JP, Brott TG, Duldner JE, Tomsick T, Leach A. Initial and recurrent bleeding are the major causes of death following subarachnoid hemorrhage. Stroke. 1994;25:1342-7. https://doi. org/10.1161/01.str.25.7.1342.

6. Risselada R, Lingsma HF, Molyneux AJ, et al. Prediction of two month modified Rankin Scale with an ordinal prediction model in patients with aneurysmal subarachnoid haemorrhage. BMC Med
Res Methodol. 2010;10:86. https://doi.org/10.1186/ 1471-2288-10-86.

7. van Donkelaar CE, Bakker NA, Birks J, et al. Prediction of outcome after aneurysmal subarachnoid hemorrhage. Stroke. 2019;50:837-44. https://doi. org/10.1161/STROKEAHA.118.023902.

8. van Donkelaar CE, Bakker NA, Veeger NJ, et al. Prediction of outcome after subarachnoid hemorrhage: timing of clinical assessment. J Neurosurg. 2017;126:52-9. https://doi.org/10.3171/2016.1. JNS152136.

9. Virta JJ, Satopää J, Luostarinen T, Raj R. One-year outcome after aneurysmal subarachnoid hemorrhage in elderly patients. World Neurosurg. 2020;143:e334-43. https://doi.org/10.1016/j.wneu. 2020.07.127.

10. de Oliveira Manoel AL, Goffi A, Marotta TR, Schweizer TA, Abrahamson S, Macdonald RL. The critical care management of poor-grade subarachnoid haemorrhage. Crit Care. 2016;20:21. https:// doi.org/10.1186/s13054-016-1193-9.

11. Vergouwen MD, Vermeulen M, van Gijn J, et al. Definition of delayed cerebral ischemia after aneurysmal subarachnoid hemorrhage as an outcome event in clinical trials and observational studies: proposal of a multidisciplinary research group. Stroke. 2010;41:2391-5. https://doi.org/10. 1161/STROKEAHA.110.589275.

12. Rowland MJ, Hadjipavlou G, Kelly M, Westbrook J, Pattinson KT. Delayed cerebral ischaemia after subarachnoid haemorrhage: looking beyond vasospasm. Br J Anaesth. 2012;109:315-29. https://doi. org/10.1093/bja/aes264.

13. Pelosi P, Ferguson ND, Frutos-Vivar F, et al. Management and outcome of mechanically ventilated neurologic patients. Crit Care Med. 2011;39: 1482-92. https://doi.org/10.1097/CCM. Ob013e31821209a8.

14. Coplin WM, Pierson DJ, Cooley KD, Newell DW, Rubenfeld GD. Implications of extubation delay in brain-injured patients meeting standard weaning criteria. Am J Respir Crit Care Med. 2000;161: 1530-6. https://doi.org/10.1164/ajrccm.161.5. 9905102.

15. Haribhai S, Mahboobi SK. Ventilator complications. Treasure Island: StatPearls Publishing; 2022. https:// www.ncbi.nlm.nih.gov/books/NBK560535/.

16. Kobayashi H, Uchino S, Takinami M, Uezono S. The impact of ventilator-associated events in critically ill subjects with prolonged mechanical ventilation. Respir Care. 2017;62:1379-86. https://doi.org/10. 4187/respcare.05073. 
17. Connolly ES Jr, Rabinstein AA, Carhuapoma JR, et al. Guidelines for the management of aneurysmal subarachnoid hemorrhage: a guideline for healthcare professionals from the American Heart Association/American Stroke Association. Stroke. 2012;43:1711-37. https://doi.org/10.1161/STR. 0b013e3182587839.

18. Lee KS, Zhang JJY, Nguyen V, et al. The evolution of intracranial aneurysm treatment techniques and future directions. Neurosurg Rev. 2021. https://doi. org/10.1007/s10143-021-01543-z.

19. Steiner T, Juvela S, Unterberg A, et al. European Stroke Organization guidelines for the management of intracranial aneurysms and subarachnoid haemorrhage. Cerebrovasc Dis. 2013;35:93-112. https://doi.org/10.1159/000346087.

20. Bederson JB, Connolly ES Jr, Batjer $\mathrm{HH}$, et al. Guidelines for the management of aneurysmal subarachnoid hemorrhage: a statement for healthcare professionals from a special writing group of the Stroke Council. Am Heart Assoc Stroke. 2009;40:994-1025. https://doi.org/10.1161/ STROKEAHA.108.191395.

21. Cheung NH, Napolitano LM. Tracheostomy: epidemiology, indications, timing, technique, and outcomes. Respir Care. 2014;59:895-915. https:// doi.org/10.4187/respcare.02971 (discussion 916-899).

22. Lin WC, Chen CW, Wang JD, Tsai LM. Is tracheostomy a better choice than translaryngeal intubation for critically ill patients requiring mechanical ventilation for more than 14 days? A comparison of short-term outcomes. BMC Anesthesiol. 2015;15:181. https://doi.org/10.1186/ s12871-015-0159-9.

23. Combes A, Luyt CE, Nieszkowska A, Trouillet JL, Gibert C, Chastre J. Is tracheostomy associated with better outcomes for patients requiring long-term mechanical ventilation? Crit Care Med. 2007;35: 802-7. https://doi.org/10.1097/01.CCM. 0000256721.60517.B1.

24. Steidl C, Bösel J, Suntrup-Krueger S, Schönenberger S, Al-Suwaidan F, Warnecke T, et al. Tracheostomy, extubation, reintubation: airway management decisions in intubated stroke patients. Cerebrovasc Dis. 2017;44:1-9. https://doi.org/10.1159/ 000471892.

25. Huttner HB, Kohrmann M, Berger C, Georgiadis D, Schwab S. Predictive factors for tracheostomy in neurocritical care patients with spontaneous supratentorial hemorrhage. Cerebrovasc Dis. 2006;21:159-65. https://doi.org/10.1159/ 000090527.
26. Szeder V, Ortega-Gutierrez S, Ziai W, Torbey MT. The TRACH score: clinical and radiological predictors of tracheostomy in supratentorial spontaneous intracerebral hemorrhage. Neurocrit Care. 2010;13: 40-6. https://doi.org/10.1007/s12028-010-9346-1.

27. Vespa PM, Bleck TP. Neurogenic pulmonary edema and other mechanisms of impaired oxygenation after aneurysmal subarachnoid hemorrhage. Neurocrit Care. 2004;1:157-70. https://doi.org/10.1385/ NCC:1:2:157.

28. Solenski NJ, Haley EC Jr, Kassell NF, et al. Medical complications of aneurysmal subarachnoid hemorrhage: a report of the multicenter, cooperative aneurysm study. Participants of the multicenter Cooperative Aneurysm Study. Crit Care Med. 1995;23:1007-17. https://doi.org/10.1097/ 00003246-199506000-00004.

29. Veeravagu A, Chen YR, Ludwig C, et al. Acute lung injury in patients with subarachnoid hemorrhage: a nationwide inpatient sample study. World Neurosurg. 2014;82:e235-41. https://doi.org/10.1016/j. wneu.2014.02.030.

30. Kahn JM, Caldwell EC, Deem S, Newell DW, Heckbert SR, Rubenfeld GD. Acute lung injury in patients with subarachnoid hemorrhage: incidence, risk factors, and outcome. Crit Care Med. 2006;34: 196-202. https://doi.org/10.1097/01.ccm. $0000194540.44020 .8 \mathrm{e}$.

31. Marhong JD, Ferguson ND, Singh JM. Ventilation practices in subarachnoid hemorrhage: a cohort study exploring the use of lung protective ventilation. Neurocrit Care. 2014;21:178-85. https://doi. org/10.1007/s12028-014-0014-8.

32. Gessler F, Mutlak H, Lamb S, et al. The impact of tracheostomy timing on clinical outcome and adverse events in poor-grade subarachnoid hemorrhage. Crit Care Med. 2015;43:2429-38. https://doi. org/10.1097/CCM.0000000000001195.

33. Dasenbrock HH, Rudy RF, Gormley WB, Frerichs KU, Aziz-Sultan MA, Du R. The timing of tracheostomy and outcomes after aneurysmal subarachnoid hemorrhage: a nationwide inpatient sample analysis. Neurocrit Care. 2018;29:326-35. https://doi.org/10.1007/s12028-018-0619-4.

34. Samuels OB, Sadan O, Feng C, et al. Aneurysmal subarachnoid hemorrhage: trends, outcomes, and predictions from a 15-year perspective of a single neurocritical care unit. Neurosurgery. 2021;88: 574-83. https://doi.org/10.1093/neuros/nyaa465.

35. Qureshi AI, Suarez JI, Parekh PD, et al. Prediction and timing of tracheostomy in patients with infratentorial lesions requiring mechanical ventilatory support. Crit Care Med. 2000;28:1383-7. 
https://doi.org/10.1097/00003246-20000500000020 .

36. Rabinstein AA, Wijdicks EF. Warning signs of imminent respiratory failure in neurological patients. Semin Neurol. 2003;23:97-104. https:// doi.org/10.1055/s-2003-40757.

37. Schreiber A, Bertoni M, Goligher EC. Avoiding respiratory and peripheral muscle injury during mechanical ventilation: diaphragm-protective ventilation and early mobilization. Crit Care Clin. 2018;34:357-81. https://doi.org/10.1016/j.ccc. 2018.03.005.

38. Boles JM, Bion J, Connors A, et al. Weaning from mechanical ventilation. Eur Respir J. 2007;29: 1033-56. https://doi.org/10.1183/09031936. 00010206.

39. Tobin MJ. Extubation and the myth of "minimal ventilator settings." Am J Respir Crit Care Med. 2012;185:349-50. https://doi.org/10.1164/rccm. 201201-0050ED.

40. Soo Hoo GW, Park L. Variations in the measurement of weaning parameters: a survey of respiratory therapists. Chest. 2002;121:1947-55. https://doi. org/10.1378/chest.121.6.1947.

41. Grinnan DC, Truwit JD. Clinical review: respiratory mechanics in spontaneous and assisted ventilation. Crit Care. 2005;9:472-84. https://doi.org/10.1186/ cc3516.

42. Bösel J, Schiller P, Hook Y, et al. Stroke-related Early Tracheostomy versus Prolonged orotracheal intubation in Neurocritical Care Trial (SETPOINT): a randomized pilot trial. Stroke. 2013;44:21-8. https://doi.org/10.1161/STROKEAHA.112.669895.

43. Nyquist P, Stevens RD, Mirski MA. Neurologic injury and mechanical ventilation. Neurocrit Care. 2008;9:400-8. https://doi.org/10.1007/s12028-0089130-7.

44. Finney SJ, Zekveld C, Elia A, Evans TW. Glucose control and mortality in critically ill patients. JAMA. 2003;290:2041-7. https://doi.org/10.1001/ jama.290.15.2041.

45. Zindrou D, Taylor KM, Bagger JP. Admission plasma glucose: an independent risk factor in nondiabetic women after coronary artery bypass grafting. Diabetes Care. 2001;24:1634-9. https://doi.org/10. 2337/diacare.24.9.1634.

46. Norhammar AM, Rydén L, Malmberg K. Admission plasma glucose. Independent risk factor for longterm prognosis after myocardial infarction even in nondiabetic patients. Diabetes Care. 1999;22:
1827-31. https://doi.org/10.2337/diacare.22.11. 1827

47. Wass CT, Lanier WL. Glucose modulation of ischemic brain injury: review and clinical recommendations. Mayo Clin Proc. 1996;71:801-12. https://doi.org/10.1016/S0025-6196(11)64847-7.

48. Michaud LJ, Rivara FP, Longstreth WT Jr, Grady MS. Elevated initial blood glucose levels and poor outcome following severe brain injuries in children. J Trauma. 1991;31:1356-62. https://doi.org/10. 1097/00005373-199110000-00007.

49. Mori H, Yamasaki K, Itoh T, Saishoji Y, Torisu Y, Mori T, et al. Predictors of prolonged mechanical ventilation identified at an emergency visit for elderly people: A retrospective cohort study. Med (Baltim). 2020;99: e23472. https://doi.org/10.1097/ MD.0000000000023472.

50. Lau LH, Lew J, Borschmann K, Thijs V, Ekinci EI. Prevalence of diabetes and its effects on stroke outcomes: A meta-analysis and literature review. J Diabetes Investig. 2019;10:780-92. https://doi. org/10.1111/jdi.12932.

51. Badjatia N, Topcuoglu MA, Buonanno FS, et al. Relationship between hyperglycemia and symptomatic vasospasm after subarachnoid hemorrhage. Crit Care Med. 2005;33:1603-9. https://doi.org/10. 1097/01.ccm.0000168054.60538.2b (quiz 1623).

52. de Rooij NK, Rinkel GJ, Dankbaar JW, Frijns CJ. Delayed cerebral ischemia after subarachnoid hemorrhage: a systematic review of clinical, laboratory, and radiological predictors. Stroke. 2013;44: 43-54. https://doi.org/10.1161/STROKEAHA.112. 674291.

53. Munoz KA, Tischler ME. The effect of a space food bar diet on body and muscle mass in normal and hind-limb suspended rats. Aviat Sp Environ Med. 1991;62:875-8.

54. Rabinstein AA, Friedman JA, Weigand SD, et al. Predictors of cerebral infarction in aneurysmal subarachnoid hemorrhage. Stroke. 2004;35:1862-6. https://doi.org/10.1161/01.STR.0000133132.76983. 8 e.

55. Roos YB, de Haan RJ, Beenen LF, Groen RJ, Albrecht KW, Vermeulen M. Complications and outcome in patients with aneurysmal subarachnoid haemorrhage: a prospective hospital based cohort study in the Netherlands. J Neurol Neurosurg Psychiatry. 2000;68:337-41. https://doi.org/10.1136/jnnp.68. 3.337 .

56. Rosengart AJ, Schultheiss KE, Tolentino J, Macdonald RL. Prognostic factors for outcome in patients with aneurysmal subarachnoid 
hemorrhage. Stroke. 2007;38:2315-21. https://doi. org/10.1161/STROKEAHA.107.484360.

57. Rajajee V. Grading scales in subarachnoid hemorrhage-many options, but do we have a winner? Eur J Neurol. 2018;25:207-8. https://doi.org/10. 1111/ene.13516.

58. Frontera JA, Claassen J, Schmidt JM, et al. Prediction of symptomatic vasospasm after subarachnoid hemorrhage: the modified fisher scale. Neurosurgery. 2006;59:21-7. https://doi.org/10.1227/01. NEU.0000218821.34014.1B (discussion 21-7).

59. Fang Y, Lu J, Zheng J, et al. Comparison of aneurysmal subarachnoid hemorrhage grading scores in patients with aneurysm clipping and coiling. Sci Rep. 2020;10(1):9199 https://doi.org/10. 1038/s41598-020-66160-0.

60. Maragkos GA, Enriquez-Marulanda A, Salem MM, et al. Proposal of a grading system for predicting discharge mortality and functional outcome in patients with aneurysmal subarachnoid hemorrhage. World Neurosurg. 2019;121:e500-10. https://doi.org/10.1016/j.wneu.2018.09.148.

61. Dengler NF, Sommerfeld J, Diesing D, Vajkoczy P, Wolf S. Prediction of cerebral infarction and patient outcome in aneurysmal subarachnoid hemorrhage: comparison of new and established radiographic, clinical and combined scores. Eur J Neurol. 2018;25: 111-9. https://doi.org/10.1111/ene.13471.

62. Chen XY, Chen Y, Lin N, et al. A nomogram for predicting the need of postoperative tracheostomy in patients with aneurysmal subarachnoid hemorrhage. Front Neurol. 2021;12: 711468. https://doi. org/10.3389/fneur.2021.711468.

63. Rass V, Ianosi BA, Lindlbauer $M$, et al. Factors associated with prolonged mechanical ventilation in patients with subarachnoid hemorrhage-the RAISE score. Crit Care Med. 2022;50:103-13. https://doi.org/10.1097/CCM.0000000000005189.
64. Torres A, Niederman MS, Chastre J, et al. International ERS/ESICM/ESCMID/ALAT guidelines for the management of hospital-acquired pneumonia and ventilator-associated pneumonia. Eur Respir J. 2017;50. https://doi.org/10.1183/13993003.005822017

65. Cook DJ, Walter SD, Cook RJ, et al. Incidence of and risk factors for ventilator-associated pneumonia in critically ill patients. Ann Intern Med. 1998;129: 433-40. https://doi.org/10.7326/0003-4819-129-6199809150-00002.

66. Warren DK, Shukla SJ, Olsen MA, et al. Outcome and attributable cost of ventilator-associated pneumonia among intensive care unit patients in a suburban medical center. Crit Care Med. 2003;31: 1312-7. https://doi.org/10.1097/01.CCM. 0000063087.93157 .06 .

67. Bouadma L, Sonneville R, Garrouste-Orgeas M, et al. Ventilator-associated events: prevalence, outcome, and relationship with ventilator-associated pneumonia. Crit Care Med. 2015;43:1798-806. https://doi.org/10.1097/CCM.0000000000001091.

68. Siempos II, Ntaidou TK, Filippidis FT, Choi AMK. Effect of early versus late or no tracheostomy on mortality and pneumonia of critically ill patients receiving mechanical ventilation: a systematic review and meta-analysis. Lancet Respir Med. 2015;3:150-8. https://doi.org/10.1016/S22132600(15)00007-7.

69. Wang F, Wu Y, Bo L, et al. The timing of tracheotomy in critically ill patients undergoing mechanical ventilation: a systematic review and meta-analysis of randomized controlled trials. Chest. 2011;140:1456-65. https://doi.org/10.1378/ chest.11-2024.

70. Huang H, Li Y, Ariani F, Chen X, Lin J. Timing of tracheostomy in critically ill patients: a meta-analysis. PLoS ONE. 2014;9: e92981. https://doi.org/10. 1371/journal.pone.0092981. 